\title{
Russian Language in the Intercultural Communication Space: Modern Problem Paradigm
}

\author{
Ella Germanovna Kulikova (Corresponding author) \\ Rostov State University of Economics, Russia \\ E-mail: kulikova_ella21@mail.ru \\ Anna Vladimirovna Kuznetsova \\ Southern Federal University, Russia \\ Pavel Vsevolodovich Zayats \\ Southern Federal University, Russia \\ Vladimir Rafaeliyevich Sarkisiyants \\ Russian State University of Justice (Rostov Branch), Russia
}
Received: 10-07-2016
Accepted: 06-09-2016
Advance Access Published: November 2016
Published: 02-01-2017
doi:10.7575/aiac.ijalel.v.6n.1p.169
URL: http://dx.doi.org/10.7575/aiac.ijalel.v.6n.1p.169

\begin{abstract}
A special role belongs to cross-cultural communication in the modern world. An attempt to limit the problem of the Russian language in Russia just with linguistic aspects, and only to culturological and political ones in the post-Soviet Union space is deeply wrong because of the whole complex of factors, relevant to the current state of the language, including both its fundamental character for the Russian culture preservation and transference and its enduring role in preservation of Russia's and neighbouring states' information and national security. A problem of the link between generations is especially topical for Russia, as the Russian society and nation are disoriented in language as a field of meanings and styles, in axiological and ethical coordinates of the world picture. Detailed investigation of the factors affecting the development of the Russian language in the cross-cultural communication space is becoming strategically important in the aspect of ensuring national security of Russia and its national unity.
\end{abstract}

Keywords: Russian language, cross-cultural communication, national security, language personality, language tolerance

\section{Introduction}

Modern linguistic paradigm raises interesting and important range of issues associated with a wide understanding of linguistic reality. The publication is prepared within the scientific project No. 16-04-00037 supported by Russian Foundation for Humanities.

One of the most productive research directions in this sense is the study of intercultural communication in the linguistic reality development and creating appropriate conceptual and terminological apparatus, including from the standpoint of intercultural studies traditions.

In this regard problems of national security gain particular importance (Volkov, 2016). In resolving national security problems an important role is played by the humanitarian factors, including philological ones (Colin, 2006). Their role is becoming especially notable in the XXI century, when the processes of society globalization are getting more and more active development, and the new information revolution is moving into the stage of forming society based on knowledge (Volkov, 2016). Nowadays the humanitarian aspects of national and international security are discussed not only at academic conferences but also at major international forums with the heads of states and governments, Ministers of Foreign Affairs, heads of United Nations and UNESCO participation. For example, the problem of the information inequality between advanced and underdeveloped countries in the modern world is becoming one of the main themes (Khazagerov, 2012). Information inequality has become one of the global problems of the civilization development in the XXI century, and solving this problem will require coordinated efforts on the part of many states. In the Western countries this problem was perceived only as a problem of digital inequality (Digital Devide), and therefore attention in its analysis was focused primarily on its instrumental and technological aspects. Humanitarian aspects of this issue, including philological ones, were ignored as a rule. But today, namely these aspects are the most important ones to resolve the present problem. There is no profit in the modern information technologies, if the population is not ready to use them and speak the language in which the society's information resources are presented. Today, this situation is 
being understood not only in the scientific circles, but it is also being raised by some political and social figures. In the case of Eurasian countries alleviating the problem of information inequality is largely associated with the need for wider dissemination not only of the English language, but also of the Russian one, which presents a lot of knowledge, technologies and other information resources of modern society. Moreover fluency in the Russian language is an important factor for the development of the individual's intellectual potential, which value will continue to grow in the XXI century.

Russian language belongs to the world's languages, i.e. the languages used as a means of international communication between peoples of different states. There are more than two and a half thousand languages known in the world, but international communication is provided by a group of the most developed world languages, it is the so-called world languages club. The language's belonging to the world languages is determined by the universal significance of the culture created in the language. (Colin, 2004). The status as the world language is legally fixed by its recognition as official or working language of international organizations or conferences (United Nations, UNESCO, etc.). Thus, Russian language is recognized as one of the six official UN languages, together with English, Arabic, Spanish, Chinese and French languages; the most important international treaties and agreements are written in Russian. The Russian language is studied in most countries. Russian language teachers are united by the International Association of Russian language and literature teachers.

Mastering the wealth of the Russian language is an important indicator of any person's cultural level, regardless of his / her field of activity. Ability to express thoughts clearly, observing all the rules of pronunciation, grammar, vocabulary means to be well understood by everybody who speaks Russian. It is very important aesthetic speech feature, as Russian language is a great miracle of culture, created by the Russian people, best Russian writers and publicists.

Nowadays, according to its prevalence the Russian language occupies the fourth place in the world. English is a leader in this comparison (it is the native language or second language for 500 million people and over one billion people speak it as a foreign language) (Goodman, 2007). The second leader is the Chinese language (more than 1350 million are fluent in Chinese - they speak Chinese almost exclusively as a native language). The third place goes to Spanish (about 360 million people speak it, including approximately 335 million speaking it as a native language). Russian language has a great internal potential for further development and rich cultural heritage. However, Russian language is the only language of the major world ones, which for the past 15 years has steadily been losing its position in all major regions of the world, and in the next 20 years this will be continued, if effective measures are not taken to support the Russian language and culture within the country and in the near and far abroad.

Strengthening the Russian language positions in the world requires not only more significant resource protection, but also it is necessary to improve the interaction between all state and public agencies and organizations, which have to support, develop and promote Russian language and culture. One should better take into account the specific features of the following major groups of foreign and Russian citizens, in addition to students of educational establishments being taught in Russian and teachers-specialists in Russian Philology:

1) the inhabitants of the nearby and far foreign countries, who have the potential to study the Russian language at home for educational, professional, household, or cultural purposes; 2) labor migrants in Russia from countries of the near abroad (Posukhova and Zayats, 2014); 3) residents of foreign countries (adults, schoolchildren, students) who can potentially come to study Russian language in Russia; 4) foreign students, trainees, postgraduate students coming to study at Russian higher and other educational establishments; 5) graduates from Russian universities and their national associations which exist today in nearly 70 countries around the world; 6) compatriots living in the near and far abroad, for whom Russian language is native.

\section{Methodology}

Synthesis of interpretive and comparative approaches applied to the studied material allows to make use of a complex of methods, with the hypothetic and deductive method, analysis, analogy and generalization, being the leading ones.

\section{Results}

The situation with the studying, dissemination and use of Russian in Russia cannot be described as favourable. A traditionally high philological culture has been steadily lost in recent years, which undermines the foundations of the whole culture of the Russian society, including the scholarly and technological culture, where foreign terminology is more often used (Scovorodnikov and Kopnina, 2016). On the initiative of the Russian President Vladimir Putin 2007 was declared the Year of the Russian Language. The status of its study and use is being described today at scientific conferences and in Russian TV programs. However, this very important and complex problem has not been really structured yet. Its connection with the problems of scientific, technological and intellectual development of our country, as well as with the problems of national security has not been displayed yet. The problem of the Russian language in the neighbouring countries of near abroad, i.e. in the former Soviet Union republics, is often viewed only as a political problem related to the situation of Russian-speaking Diaspora.

In the analysis of the problem, it seems appropriate to consider the following four basic aspects.

1.The Russian language represents a fundamental basis for Russian culture and therefore is a very important national treasure of our country, which should be under special protection from the state. That is why Russian language is considered as one of the objects of Russia's information security in the information security Doctrine of the Russian Federation (Information Security Doctrine of the Russian Federation, 2000). 
2.The Russian language itself is one of the most important factors of information security in our country, as it is intimately connected with the development of its intellectual potential necessary for further innovative development of Russia in conditions of the formation of a new technological order and formation of the society based on knowledge and high international competition (Frolova et al., 2015).

3.The Russian language role in the information security of Eurasian states surrounding Russia, particularly those which until recently were republics of the Soviet Union and long-term cultural, scientific, economic and other ties associate them with our country. Not only the interests of the Russian Diaspora in those countries, but also the interests of their indigenous population, i.e. the so-called titular nation should be taken into account.

4.The role of the Russian language in the solution of ensuring international information security problems (Colin, 2004).

In determining the role and place of Russian in the system of information security the most important factors are the following:

1.In the Russian Federation, Russian is the source language for over 130 million people and it is used as the primary means of communication between people in a multi-ethnic state, as well as the main state language, in which all the functions of government are performed. Also it preserves and transmits the history and culture of the Russian people and those of the former USSR peoples to future generations. (Belkanov, 2007). This function of the Russian language is the most important function in the public consciousness (Steinthal, 1855). Therefore, in most cases, the problems of the Russian language are considered only as cultural problems, although it is not so, because the subject field of these problems is much more extensive. For example, Russian is the main language of fundamental science and higher education system in Russia. Certainly, research and training of specialists with higher education in our country is conducted in the languages of other peoples of Russia. However, the vast majority of scientific knowledge is presented in the Russian language, and therefore its role is crucial here. This role becomes especially important at the modern stage of civilization development, when the society based on knowledge, new technological system is being formed and presented in Russia by means of the Russian language.

2. In the neighboring countries the situation concerning the Russian language today is fundamentally different. Here it acts mainly as the language of interethnic communication. In the Baltic States it is still serving as the main communication means not only within the Russian-speaking Diaspora, but also among representatives of the titular nations - the Latvians, Lithuanians and Estonians.

As for the status of the second state language, the Russian language has such status only in Belarus, and in other countries, this status was lost after the collapse of the Soviet Union. However, Kazakhstan and Kyrgyzstan have declared Russian as the language of official documents, but the majority of the population in these countries in everyday communication doesn't use the Russian language. The use of the Russian language in the education system of the CIS countries continues to decline. All in all, in the former Soviet republics, the Russian language today is native for about 26 million people, and almost 60 million speak it.

3. In the CIS countries Russian language is studied and used now much less in comparison to the days of the Soviet Union when its government implemented the policy of support of Russian culture abroad.

Today such policy in Russia is almost completely absent, even concerning Belarus, which is formally a part of the new Union state. A completely different situation is in China, where interest to the Russian language, for obvious reasons, is continuously growing. Today, the Russian language in China is being studied by two million people at least. Of course, in the CIS countries Russian language is used by our Diaspora, but no support for this from modern Russia is provided.

Therefore, the representatives of this Diaspora quickly assimilate with the local population, and their children generally do not have the skills of Russian speech. The exception is only the situation in Israel, where the positions of the Russian language in society are not only extremely durable, but in recent years continue to strengthen. The fact is that the Russian-speaking population of Israel currently constitutes about $30 \%$ of the total population and has a strong influence on the internal policy of this country. There is even an opinion on how to give the Russian language the status of the second state language on a par with Hebrew, because many immigrants from Russia don't speak good Hebrew. And this opinion is based not on political consideration but on pragmatic one.

An attempt to limit the problem of the Russian language in Russia with its linguistic aspects, and in the former Soviet Union to cultural and political aspects is deeply wrong, as this is a complex issue and, that is very important, it is closely connected with the problems of ensuring national security of Russia and other states surrounding it.

In the space of the former Soviet Union the Russian language is exposed to certain threats, the that almost all former Soviet republics, except Belarus, provide public policy to oust the Russian language from all the spheres of public life and replace it by national languages.

In foreign countries the status of the Russian language also is not good. In the time of the Soviet Union about 50 million people studied the Russian language abroad. The necessary funds were allocated to support and stimulate this process, training literature and fiction were printed and distributed, i.e. purposeful government policy was provided and resulted in the growing reputation of our country as a great power in the world community. It contributed to the spread of Soviet culture in other countries. Typical examples are Cuba and Mongolia. During the visit to Mongolia in 2014 Russian President Vladimir Putin spoke Russian to the deputies of the Mongolian Parliament, and translation of this speech into Mongolian was almost not necessary as many MPs studied at Russian universities and therefore knew 
Russian. Nowadays, however, Russian-language information space in the CIS countries has significantly decreased. This negative trend also represents one of the threats for the Russian language in the field of intercultural communication for the following reasons.

1. Russian-speaking space abroad is the main condition for spread of the influence of Russian culture, spiritual values, science, education and technology in foreign countries, many of them would like to develop their cooperation with Russia. For example, Spain, Portugal, Brazil, Greece and even Singapore believe the current level of their cooperation with Russia is clearly insufficient. At present the countries of Latin America open good prospects for cooperation with Russia in the sphere of technology, science and education. But for this, technical specialists, scientists, teachers and businessmen of these countries should speak Russian rather well and communicate with their Russian partners without interpreters. Therefore, the development of Russian-language information space in these countries could become a good stimulus for the development of such cooperation that could help create a multicultural world in the future.

2. Russian language is an important factor for Russia to cooperate with its diasporas in foreign countries. Currently, the level of this interaction is clearly unsatisfactory, and the potential for Russian-speaking diasporas abroad in the interests of Russia is almost never used, although it is very significant. Several hundred thousand Russian scientists and specialists occupy prominent positions in American companies.

3. The Russian language is one of the six major languages of international cooperation, which is recognized by the most authoritative international organizations: United Nations, UNESCO, World Health Organization, United Nations Environment Programme, etc. However, in international practice, the scope of its use today is very limited.

There is a rather serious threat to the Russian language in Russia itself today. First of all, it is a blockage of speech and writing with English borrowings, which began after the collapse of the USSR, and is increasingly used not only in advertising and the names of commercial enterprises, but also in everyday communication and even in the speeches of public figures and politicians (Brusenskaya and Kulikova, 2016). Moreover, hybrid English-Russian phrases not corresponding to any standards of Russian grammar are quite often used today. This not only pollutes the literary and everyday Russian language, but penetrates into people's consciousness, bringing to it elements of the alien culture.

Unfortunately, there are no effective measures to counteract this process in Russia today because it is not yet adequately perceived as a danger of the information threat. Although this threat is quite feasible, and it is growing.

France would be a good example in solving this problem, where the concern to preserve the purity of the French language is one of the main tasks of the Institute of France, performing the functions of National Academy of Sciences. Therefore, there are not any American borrowings and, with rare exceptions, texts and terms in other languages in modern French literature, including newspapers and magazines. Many authors refer to the example of France so that it could serve as a model of internal language policies, because without such regulation the value of the native language is often not perceived as a part of the national identity.

Administrative liability for the use of foreign words and phrases when there are Russian analogues is provided by the Law "On the Russian language as the state language of the Russian Federation" adopted by State Duma. But, firstly, it is unclear what is considered an analogue in the presence of the inevitable pragmatic differences between native and borrowed units, and secondly, an analogue, is often a borrowing, too, but assimilated. And besides, as practice shows purism against foreign elements is successfully ignored by usage (Khazagerov, 2014; Khazagerov and Glushko, 2015; Kulikova and Kuznetsova, 2015; McMillan, 1996).

The Russian language is more and more filled with slang expressions typical for the criminal world which are frequently used today, not only by Russian youth but also by the older generation. Often we hear them in public speeches of our politicians. And the use of obscene expressions, which in recent years has become fashionable among Russian youth, does seem to be unacceptable. This is very serious and requires an adequate response not only from the cultural community of Russia, but also from its government.

It is very important to focus our attention on the sharp decline in the quality of the study of Russian language and literature in secondary school. This also applies to the training programs, and to the unacceptable number of hours of training, which is now provided by the state educational standards for the study of these basic disciplines.

This problem is now so acute that it is already spoken and written about not only by teachers and experts in the field of humanitarian sciences, but also by physicists and mathematicians who understand that the language is an important instrument for the development of skills for abstract thinking and modeling the world around us (Steinthal, 1855). Therefore, good knowledge of the language rich in its expressive power is a prerequisite for the development of a person capable of creative thinking (Haugen, 1966). Fortunately, the Russian language with its expressive possibilities is one of the richest one in the world. It is our national wealth, which must be especially protected. The problem of the quality of studying the Russian language and literature at a Russian secondary school is only the "top of the iceberg", i.e. a part of another, much more difficult problem. It is the problem of Philological culture and Philological education in Russia, which are in very poor conditions at present.

According to the opinion of authoritative experts (Belkanov, 2007) the system of classical philological education that existed in Russia is almost completely destroyed today and its restoration will take many years. The reason is not only the loss of educational traditions during the years of restructuring in Russia, but also in the lack of philologically high- 
educated teachers today (Khazagerov, 2010). Moreover, modern pragmatists from education ministry put into doubt the necessity of obtaining a good philological education itself. And this is extremely dangerous for the future of our country. After all, without good philological education it is impossible to provide the highest quality of education in general, neither humanitarian education, nor scientific one. The older generation of our country remembers that a wellread person, fluent in the skills of oral and written speech not only in Russian, but also in two or three foreign languages has always been considered as highly educated in Russia. Unfortunately, the number of highly educated people among the Russian intelligentsia in recent years has declined.

\section{Discussion}

The link between generations in society is provided through the language, and this problem is extremely acute and relevant to modern Russia.

Apparently, today the Russian society and nation are losing values and moral guidelines, and consequently the language, which serves as a means of orientation in the field of meanings and styles. And this is a clear threat to national security, which cannot be ignored. One of the most relevant and strategically important problems of national security of modern Russia is the problem of ensuring its national unity. Unfortunately, the meaning and importance of this problem has not been well understood in Russian society yet. Moreover, according to presentations on TV of some representatives of our scientific elite, the essence of the problem remains unclear even in theory. But the unity of the nation is the most important condition of multicultural state existence.

A very important factor in solving the problem of achieving national unity is a national language, in which all the population of the country must speak. According to psychological studies the language in which a person not only speaks, but also thinks, on a subconscious level creates his /her spiritual values associated with this language. And it is the unity of spiritual values, that is a necessary condition to ensure national unity.

The main distinguishing feature of a nation is the unity of the vital interests of the people living together, not their ethnic, political or religious affiliation. The peoples in Russian Federation speak more than one hundred languages and dialects, profess different religions, hold different political views, occupy different economic and social statuses. Thus every Russian faces the problems of intercultural nature: they are cultural and religious differences, ethnic stereotypes, prejudices, etc. As the direction in Russian science, intercultural communication began to develop since the early 90 -ies of the $\mathrm{XX}^{\text {th }}$ century, and interest in the problems of intercultural communication is extremely high. The initiators of the intercultural communication research in Russia have become foreign language teachers, who first realized that knowledge of a foreign language is not enough to communicate effectively with representatives of other cultures. The practice of intercultural communication has shown that even deep knowledge of a foreign language does not exclude misunderstandings and conflicts with native speakers, so foreign language teaching has been complemented by the training discipline "Country Studies" which introduces students to the history, customs, traditions, social organization of the target language country. However, only a theoretical acquaintance with the appropriate culture is not enough for conflict-free communication with its representatives. Knowledge of the cultures of the other representatives allows to resolve a situation of intercultural misunderstanding quickly and effectively, organize the working process in multinational teams, etc. Vast experience in solving problems of intercultural communication has been accumulated abroad, and this experience should be fully tapped in Russia. In recent years series of textbooks on intercultural communication have been published in Russia, authors of these textbooks (Grishaeva, and Tsurikova, 2008; Gudkov, 2003; Persikova, 2002; Sadokhin, 2005, etc.) investigate the main concepts, theories and methods of this science. It should be noted that the interest in this problem appeared in the second half of the XVIII century in the framework of ethnology, when for the first time in Russian social thought, questions about the role and place of Russia among other nations, the historical roots of Russian people, about the peculiarities of Russian culture, etc were raised. The movement of Slavophiles played an important role in the formulation and solution of ethnic problems in Russian culture. Based on the idea of the Messianic role of Russia in the world, they regarded as their task the development of national consciousness of Russian people, the preservation of their national identity. Interests of the group always stood above the interests of the individual in our culture, so plans, goals and interests of an individual are easily suppressed in it. Russians believe that first you are to set up something socially significant for the group, and common interests are more important than personal ones, and in this case these common interests will begin to operate in favor of a person at his / her own discretion. The business, the skill, the wealth, and the freedom and law which constitute the foundation of these values (in the West) were not important for him /her. In the Soviet period of development international relations were a specific area of research. They were usually studied on the basis of statistical data of everyday behavior and specific actions of the individuals. Thus, friendship between nations was assessed by a number of participants of different nationalities in major all-Union construction sites or by the number of interethnic marriages. In general, studies of this period were politically oriented. In a society of strict hierarchy, which was the Soviet Union, only monologue dominated, and there was no need for rhetorical skill.

Like in the Middle Ages, when the main word was the citation word (the Bible, and later the Marxist-Leninist doctrine), the main thing was proximity to the source of correct ideas. Analysis of Russian culture values shows that they were formed for the non-market economy and subsistence farming. In the same way Russian character was formed, which made the Russian people market unconscious. In modern Russia changes are connected with the formation of market economy. In extension of dialogue, polyphony, the right to truth, which depend not only on the hierarchical boss seat level, attitude towards communication has changed. Hierarchical system of communication in Soviet Russia, where its main component was an order, began to transfer into the system of democratic communication, based on persuading 
(Khazagerov, 2011). These problems are not only new to our society, but also rather complicated (Khazagerov, 2013). They assume a much more intellectual level in the managerial system. In the past, when the system was repressive and communicative, it was enough to rely on external coercion. Today only individual's own desire can be such coercion. Methods of economics, internal and external policy of the country, the national character have been changed, new values have been introduced into the foundation of Russian culture and old values have been reevaluated. A new communicative space is generated by equivalent independent from each other participants. In this new situation there is a new problem in the society - how to combine social groups with autonomous behavior into a single type of behavior, how to reach consensus (not by chance this word has become a favorite one in the speeches of politicians of the postSoviet time). Social reforms have resulted in considerable change in the cultural image of Russia.

During the last few years completely new social groups have appeared: businessmen, bankers, political leaders of different movements, Russian employees of foreign firms, etc. The establishment of a completely new type of business culture, formation of new understanding of social responsibility of business to the client and society, change of the society in whole occur. The end of the "cold war" between the East and the West has significantly expanded trade and economic relations between them. In each country from year to year, a number of people with economic ties outside of their culture grows. Becoming participants in many cross-cultural contacts, people interact with other cultures that are completely different from each other. Differences in languages, national cuisine, clothing, social habits, attitude towards their work often make these contacts difficult and even impossible. Diverse international contacts of managers and businessmen at all levels showed that the success in any form of international activity is largely dependent on the training quality of domestic specialists in the field of intercultural communication. For their effective activity, they must consider specificity of culture of their partners and host countries.

The process of intercultural communication develops with great difficulties, because of a huge number of obstacles and limitations. Considering the modern situation in the Russian political space in the last decades, starting from 1991, after the collapse of the USSR, it is easy to detect a range of negative trends developed in the context of intercultural interaction.

Russia and countries which were formerly parts of the Soviet Union are connected with long common history. In the process of interaction cultural traditions were interlaced, mutual respect and understanding of each other were formed. For almost a century these states were a single entity. In this period along with preservation of national languages the state language of interethnic communication was the Russian one. Language is a communication tool, a means of expression. Language serves communication, it is an important, the most explicit, the most formal and socially approved kind of communicative behavior. In the context of intercultural communication the language is a key tool used for communication, creating a unified communication space, and it provides keeping and transfer of culture, traditions, and social awareness. Language is the guardian of its people. It allows person to divide people into "us" and "them".

Language has endless possibilities for formation of tolerance and political correctness. Political correctness appeared when it was necessary for people speaking English to find new ways of linguistic expression instead of those which hurt the dignity of the individual, infringe on his / her human rights relating to any of person's characteristics - race, nationality, sex, age, health and mental condition (especially in those cases where any properties of the person do not fit into the existing standards). Naturally, the spread of political correctness ideas do not eliminate evaluation (including negative) nominations for the people according to all mentioned features from emotionally saturated language. However, in such cases, an addresser uses intentionally nominations which are not politically correct, because the addresser understands their pragmatic features. In neutral and positive contexts politically correct expressions are used intentionally. Modern ideas of political correctness are aimed at overcoming stereotypes discriminating a person. Linguistic consciousness is formed by the stereotypes, i.e. the socio-psychological phenomena. Stereotypes are selective, not presenting a complete picture of the world and being an expression of individual fragments of this world. Stereotypes are special forms of information processing, keeping knowledge and assessments, "concepts of orienting behavior". Stereotypes are considered to have the cognitive function, consisting of generalization and ordering information, the affective function, which consists of the opposition between "us" or "them", the social function (the distinction between "intra-group" and "outer-group" leading to social categorization and the formation of structures on which people behave in everyday life). Politically correct behavior (including linguistic one) demands the recognition of universal equality, justice, self-reliance, preference of the person's spiritual world under accidental characteristics of his/her appearance, loyalty (but not regret) to any people's minorities.

Language stereotypes often hinder widespread of progressive ideas in society. Such opposition may be determined by the language system conservatism, that inhibits the development of the linguistic tolerance. Language stereotypes are determined by the language picture of the world and cognitive abilities of the language (Broccias, 2006; Dixon, 2010; Goodman, 2006), so they can not be reshaped so quickly, as, for example, public relations. Hence, language and discourse can influence tolerance / intolerance of language person.

Attempts to create a common language picture of the world provided some dominant, which was determined with the national-cultural traditions and the prevailing social ideology, i.e. invariant part. Structuring a comprehensive picture of the world is possible only through establishing a hierarchy of meanings and values for individual linguistic identity. Linguistic personality is characterized by a certain vocabulary, having some frequency of use and filling abstract syntax model. If models are rather typical for a representative of this linguistic community (Beck, 1992), the vocabulary and speaking manner may indicate his belonging to some definite society, the level of education, type of character, gender 
and age etc. Linguistic repertoire of such person, whose activity is related to implementing a dozen of social roles, must be understood by taking into account speech etiquette adopted in society.

In modern conditions the educational institutions perform the function of ethno-cultural consolidation of the society and ensuring its sustainability. Prospective and effective approaches to teaching that promote intercultural dialogue in the educational process - the creation and introduction of integrated courses with ethno-cultural component into educational process; the development of individual innovation programs, taking into account the national, regional and local specifics; development and implementation of specialized courses for the study of ethno-cultural heritage of the peoples of Russia - are found. For example, nowadays an important aspect is found: a problem for North Caucasian peoples is not russification, but poor knowledge of the Russian language. On the other hand, knowledge of some ethnocultural constants is very important for contact and empathy between the teacher and students. These ethno-cultural constants are customs, national cuisine, etiquette, national literature, i.e. all that creates a precedent background for full communication in the learning process.

In the age of globalization, economic interdependence of states, active migration and integration, tolerance becomes a necessary condition for the survival and development of the world community, ethnic, religious, national and cultural cooperation between the states (Featherstone, 1995).

Tolerance is universal value, it should play an important role in resolving ethnic and religious conflicts, prevention of acts of terrorism and violence, nationalism, racism, antisemitism. The important role and place of tolerance in modern society is determined in a number of international documents. A "Declaration of Tolerance Principles" was adopted on 16 November 1995 in Paris, where tolerance was proclaimed as moral obligation, political and legal necessity (article 1). The problem of tolerance is initially interdisciplinary, equally applies to linguistics, sociology, ethnology, religious studies, ethics, philosophy, political science, general and social psychology and other humanities. Each of them investigates the problem of tolerance in different contexts, which are reflected in the attempts to define this important problem. In general, tolerance is seen as a manifestation of adaptive degree of the cognitive schemes flexibility of other individuals perception, their views and actions offered by culture and subcultures. Implicit concept of tolerant individual may be substantially varied in different social and psychological groups, researches about tolerance should also consider gender differences.

For example, historically the South of Russia covers with its borders hundreds of ethnic groups that are not just neighbors to each other, but for centuries have coexisted together that is a vital condition for the preservation of each of them and Russia in whole. In the interaction different cultures not only complement to each other but also enter into complex relations with each other, and each of them finds its specificity and identity. In their contacts cultures are mutually adapted in the form of borrowing their best "products". Changes caused by these borrowings force a person of a given culture to adapt to them, learning and using new elements in his/her life.

The functioning of languages in a multicultural society (Giddens, 1990) is driven by two needs of human nature, the need for identity (language acts as one of the markers of ethnicity) and the need for understanding satisfied in the process of communication. The fate of the national languages with the dominance of Russian can be different: 1) they can obtain the status of a regional language; 2) they can play the role of everyday communication language; 3) there can be a situation of linguistic assimilation which is contributed by a number of people, strict language policy, and cultural factors.

Today all the nations and nationalities have experienced social, political and cultural influence on the part of other nations and nationalities. It is implemented in different ways: through the exchange of cultural achievements, direct interpersonal contacts in the academic and student environment, in the business sector, through migration and tourism. With the development of the world community, channels and opportunities of intercultural communication are expanded, that is reflected in the increasing socio-cultural significance of the common achievements of civilization for all humanity. Intercultural interaction is continuously evolving, reaching the growth of mutual understanding in different spheres of social life and at different levels. In Russia the problems of intercultural communication are in the focus of many studies. Traditionally, interaction between representatives of different ethnic groups coexisting within a single state is investigated. Ethnic tensions in modern Russia, as a consequence of the Soviet collapse, economic crisis, intense migration and other factors stimulated the study of various aspects of ethnic and national consciousness affecting multicultural contacts.

\section{Conclusion}

The analysis of the phenomenological status of the Russian language in intercultural communication, including from the point of view of ensuring national security of Russia and Eurasian countries surrounding it allows to make the following main conclusions:

5.1. The problem of preservation and use of the Russian language in social life, science, education and culture of Russia and other countries that are its closest neighbors, is extremely sharp and relevant today, as it is directly connected with ensuring their information security. Unfortunately, this problem is still not considered from this point of view both in Russia and other countries, and attempts to reduce it to purely linguistic and political aspects only mask the problem and do not contribute to its solution.

5.2. Russian language is the most important part of the national wealth of Russia, and therefore needs to be protected by the state as one of the objects of the system ensuring the country's national security. 
5.3. Nowadays there are very feasible and serious enough threats for the Russian language, both in Russia and abroad, particularly in the young independent states, former parts of the USSR. As a result Russian-speaking space in these states is rapidly being reduced, and near the borders of Russia a whole generation of young people who do not know the Russian language and culture, history, scientific and technological achievements is growing up. And it will definitely become a serious obstacle for development of cooperation between Russia and neighboring countries in the future.

5.4. The preservation of the Russian language and Russian education in the post-Soviet space is a necessary condition for the restoration of national unity of Russia, because Russian nation is divided today today. Solving this important problem, which has become part of the problem of ensuring the national security of our country requires deliberate and consistent state policy of Russia which is absent at present.

5.5.Russian-language information space abroad does not have the necessary support from Russia and therefore is quickly being reduced today. Without changing this trend, according to experts, in 25 years the Russian language may lose its status as the world language, because the number of its speakers will be reduced to a level of the early twentieth century.

5.6. It is necessary to take urgent measures to change the situation with learning the Russian language and literature at Russian schools, and with the attitude to philological education existing in our country today in order to prevent further linguistic, cultural, and spiritual degradation of the Russian society. The Russian language and Russian literature, as well as mathematics and history, should be the basic disciplines in Russian education again.

Language personality exists in the space of culture reflected in the language, forms of social consciousness at different levels (scientific, everyday, etc.), in behavioral patterns and norms, artefacts, etc. The main role in the culture belongs to the values of the nation. Cultural values form a system in which there are universal and individual, dominant and additional meanings. They are reflected in the language, or more precisely, in the meanings of words and syntactic units, in phraseology, in proverbs and sayings, precedent texts. It is possible for each culture to develop some parameters which are able to be its original coordinates, original value signs. These value characteristics are fixed, on the one hand, in linguistic stereotypes, on the other, such characteristics can be researched as concepts, and here the focus is put on the methodology of cognitive linguistics. The main correlation in the ethnic and cultural point of view becomes the correlation "own - alien", and "own - another". In the XXI century, having become stronger in national culture and spirituality, the individual finds access to the creatures of another nation spirit, understands their spiritual strength and achievements. In order to be interesting for others, a person needs to be himself. That is why the phenomenological status of the Russian language in intercultural communication can be defined as a complex multidimensional object that requires state regulation and deep research not only in linguistic paradigm, but also in other humanities.

\section{Acknowledgements}

The publication is prepared within the scientific project No. 16-04-00037 supported by Russian Foundation for Humanities.

\section{References}

Beck U. (1992). Risk Society: Towards a New Modernity. London: Sage, 260.

Belkanov, R. (2007). University of Modern Philological Education. Higher Education in Russia, 4, 72-79.

Broccias, C. (2006). Cognitive approaches to grammar. In Broccias, C. (Eds.), Cognitive Linguistics: Current Applications and Future Perspectives. Berlin-NY.: Mouyon de Gruyter, 81-117.

Brusenskaya, L.A., \& Kulikova, E.G. (2016). Ecological Linguistics. Rostov-on-Don: Flinta-Science, 186.

Colin, K.K. (2004). Globalization and Culture. Bulletin of Library Assembly of Eurasia, 1, 12-15.

Colin, K.K. (2006). Information Security as a Humanitarian Problem. Open Education, 1(54), 86-93.

Declaration of Tolerance Principles. (2005, November 15), [Online]. Available from http://fbg.herzen.spb.ru/images/doc/normdok/toleran/dekltoler.doc (July 7, 2016).

Dixon, R.M.W. (2010). Basic Linguistic Theory. V.1. Methodology. Oxford: Oxford University Press, 381.

Featherstone, M. (1995). Undoing Culture: Globalization, Postmodernism and Identity. London: Sage, 192.

Frolova, A.S., Lubsky, A.V., Posukhova, O.Y., Serikov, A.V., \& Volkov, Y.G. (2015). Ideological Grounds for Settlement of Inter-Ethnic Relations in Modern Russia: Competition of Ideas and Ideology of Humanism. Mediterranean Journal of Social Sciences, 6(4), 58-63.

Giddens, A. (1990). Consequences of Modernity. Cambridge: Polity Press, 186.

Grishaeva, L.I. \& Tsurikova, L.V. (2008). Introduction into the Theory of Intercultural Communication. Moscow: Publishing House "Academy", 352.

Goodman, S. (2006). Word and Image. In Goodman, S. (Eds). The Art of English. Basingstoke: Palgrave Macmillan, 244-298. 
Goodman, S. (2007). Market Forces Speak English. In Maybin, J.; Mercer, N. \& Hewings, A. (Eds.), Using English. London: Routledge, 141-180.

Gudkov, D.B. (2003). Theory and practice of intercultural communication. Moscow: Publishing House "Gnosis”, 228.

Haugen, E. (1966). The Ecology of Language. Stanford, CA: Stanford University Press, 159-190.

Khazagerov, G.G. (2010). Scientific Discourse Lost of Sense as Objective Process. Sociological Journal, 10, 5-20.

Khazagerov, G.G. (2011). Self-destruction of Totalitarian Rhetoric: Crisis of Symbols (Soviet experience). Sociological Journal, 4, 69-83.

Khazagerov, G.G. (2012). Communicative Topography of Public Opinion. Sociological Journal, 1, 5-16.

Khazagerov, G.G. (2013). Phenomenon of Forced Manipulation in the Totalitarian Culture. Sociological Journal, 1, 126-140.

Khazagerov, G.G., \& Glushko, A.M. (2015). A Systematic Approach to Qualities of Speech (for example consistency). Humanitarian, Socio-economic, and Social Sciences, 2, 394-399.

Kulikova, E.G.. \& Kuznetsova, A.V. (2015). Modern Russia: Communicative Situation under Postmodern Era. Asian Social Science, 11(7), 284-294. DOI:10.5539/ass.v11n7p

McMillan, S. (1996). How to be a Better ... Communicator. London: Industrial Society. Kogan Page, 128.

Persikova, T.N. (2002). Intercultural Communication and Corporate Culture.Moscow: Publishing House "Logos", 224.

Posukhova, O. Y., \& Zayats, P.V. (2014). Social Engineering as a Mechanism of Optimization of Human Resources Management in Rostov Region. Middle East Journal of Scientific Research, 19(3), 424-428.

Sadokhin, A.P. (2005). Introduction into the Theory of Intercultural Communication. Moscow: Higher School, 310

Scovorodnikov, A.P., \& Kopnina G.A. (2016). Linguistics of Information-psychological War: to Substantiation and Definition of Concept. Political Linguistics, 1(55), 42-50.

Steinthal, H. (1855). Grammatic, Logic und Psychologie. Berlin:_F. Dümmler, 300.

Volkov, Yu.G. (2016). Images, Ideology and Humanism in Contemporary Russia. Moscow: Publishing House "KnoRus Company", 208. 